\title{
CHOKELESS WELDING TRANSFORMER WITH LOAD SERIES MOTOR
}

\author{
Shivanand B Katagar ${ }^{1}$, Rajendra M Salokhe ${ }^{2}$, Sharad R Jadhav ${ }^{3}$, Chetan D. Patil ${ }^{4}$ \\ ${ }^{1}$ Student, Electrical Engineering Department, SIT COE Yadrav, Maharashtra, India \\ ${ }^{2}$ Student, Electrical Engineering Department, SIT COE Yadrav, Maharashtra, India \\ ${ }^{3}$ Student, Electrical Engineering Department, SIT COE Yadrav, Maharashtra, India \\ ${ }^{4}$ Assistant Professor, Electrical Engineering Department, SIT COE Yadrav, Maharashtra, India
}

\begin{abstract}
Welding is a materials-joining process that produces coalescence of materials by heating them to the welding temperature with or without the application of pressure or by the application of pressure alone, and with or without filler metal. It is used to make welds. It is observed that the welding transformer with choke or movable core is having large size, so to reduce the size we are replacing the choke with one coil. This coil functions same as the choke. This coil helps to reduce the size as well as the cost of the welding transformer. The forced air cooled transformer consists of an exhaust fan which rotates at a constant speed whether the welding work is going or not. So, the more energy will be wasted there. To avoid this, the load series motor is used. The load series motor as the name suggests is a motor, which is to be connected in series with a load. The load series motor, which shaded pole motor but designed in such a way that if connected in series with load, it will run and speed of such motor will be proportional to the load current. The ordinary exhaust fan motor can be, easily replaced by the load series motor.
\end{abstract}

Keywords: Rotary Switch, and Load Series Motor.

\section{INTRODUCTION}

Welding Transformers are used in AC machines to change alternating current from the power line into a low-voltage, high amperage current in the secondary winding. Combinations of primary and/or secondary taps on the welding transformer are commonly used to provide adjustment of the welding current, as well as adjustment of secondary voltage. Transformer ratings for AC machines are expressed in KVA (kilovolt-amperes) for a specified duty cycle. This duty cycle rating is a thermal rating, and indicates the amount of energy that the transformer can deliver for a stated percentage of a specific time period, usually one minute, without exceeding its temperature rating. The RMS Short Circuit Secondary Current specification indicates the maximum current that can be obtained from the transformer. Since heating is a function of the welding current, this parameter gives an indication of the thickness of the materials that can be welded. Welding transformer may be single phase, two phases, or three phases. For low current supply, single phase transformer is used. Therefore they are used for thinner section welding with minor diameter electrode. For high current two phase and three phase supply transformers are used. They are used for thicker welding plates. Transformer may be oil cooled or air cooled. Big transformers are always oil cooled. Transformer may be AC or DC generator and generator may be oil/gas operated. Current range (AC welding transformer) -600 amp. Open circuit voltage 70v-100v. Basically two types of the power source can be used for arc welding machine purpose that is AC transformer and DC generator rectifier. Power source consists of the two cables, electrode cables and earthling clamps; electrode holder stringer and electrode or rod. [2][1]

1.1 The Size of Welding Transformer is Large due to the Following Reason

1.1.1 Three Phase Movable Core Welding

\section{Transformer}
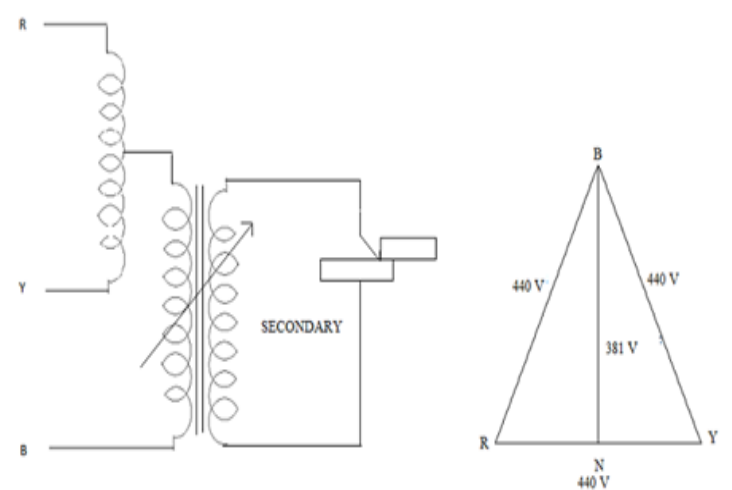

Fig -1: Movable core type transformer

The center tap of two phase lines by an auto transformer, and the third phase is directly connected to give approximately $381 \mathrm{~V}$ of a $440 \mathrm{~V} 3$ phase AC supply to the primary of the step down transformer. This type of welding transformer has a movable core in between the primary and secondary coils, which diverts the flux through it to control arc current. The primary current in the 2 phase, lines is half of the current in the third phase. Such transformers are wound for any capacity small and big much vibrations are 
produced due to movable core, causing wear and tear and thus reducing the life if not fitted and handled properly the step less current variation can be obtained to adjust for particular job.

\subsubsection{Self-Choke Type}

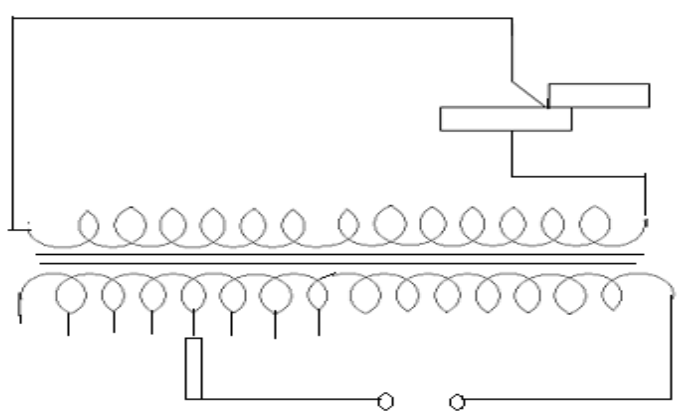

Fig -2: Self-choke type

This is a high leakage reactance step down transformer electrically single phase type, designed to work either $250 \mathrm{~V}$ or on $440 \mathrm{~V}$.The current is regulated by regulating the OC voltage on secondary side of the welding transformer. In this type the flux density will be varying with change of primary turns. The flux densities at lower currents will be much less and hence no load loss will be very small when compared with other transformers. The primary turns are varied with a rotary switch. The two primary and secondary are wound separately and are housed as shown in Fig. below. To provide a path for leakage flux stampings of appropriate size are increased in between primary and secondary coils. The OC voltage is generally between 40 and $70 \mathrm{~V}$ these types are used for light duty works and up to 200A rating. At low voltage the voltage the power is better but the maintenances of are requires more skill. It is observed very difficult to work with very small rods and is generally suitable for 10 SWG electrodes for M.S. work.

Because of these two reasons the size of welding transformer is large. the transformer is static device but the size of welding transformer is large than induction motor for the same capacity. [2][4]

\section{CIRCUIT DIAGRAM}

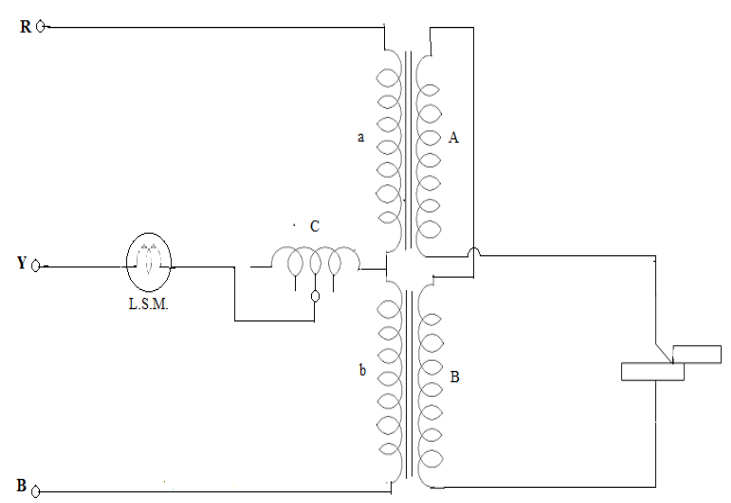

In ordinary welding transformer, either a separate choke is required to be provided to control the arc current or a separate auto transformer or the step down transformer with movable core is required to be provided. Because of this the size of the welding transformer becomes large. To overcome this, a tapped coil is inserted in the central limb of core. That is coil ' $\mathrm{C}$ '. The size of the core required for this is slightly bigger than the original three limbed core. The turns of this coil is taken as $21 \%$ of the other two coils.

Load series motor is a better substitute for an exhaust fan in forced air cooled welding transformer. The forced air cooled welding transformers are provided with a small fractional HP single phase motor of capacitor type or shaded pole type to work as an exhaust fan to cool down the windings. This fan starts running immediately when the welding machine is switched on to the supply. Generally the welding transformer has maximum duty cycle of $60 \%$.The exhaust fan runs at constant speed whatever the current is drawn from the machine for welding or even when no welding work is going on. The load series motor is single phase motor to be connected in series with the load is a current controlled shaded pole motor, designed in such a way that if connected in series with the load, it will run and the speed of such a motor will proportional to the load current that is arc current. This special motor is very suitable for forced air cooled welding transformer. The ordinary exhaust fan can be very easily replaced by the load series motor.[2]

\subsection{Working Principle}

Welding transformers are step down transformers, are designed to reduce electrical voltage. Their primary voltage is greater than their secondary voltage. This kind of transformer "steps down" the voltage applied to it. Step down transformers convert electrical voltage from one level or phase configuration usually down to a lower level. They can include features for electrical isolation, power distribution, and control and instrumentation applications. Step down transformers typically rely on the principle of magnetic induction between coils to convert voltage and/or current levels. Welding transformers are made from two or more coils of insulated wire wound around a core made of iron. When voltage is applied to one coil (frequently called the primary or input) it magnetizes the iron core, which induces a voltage in the other coil, (frequently called the secondary or output). The turn's ratio of the two sets of windings determines the amount of voltage transformation. An example of this would be: 100 turns on the primary and 50 turns on the secondary, a ratio of 2 to 1.Step down transformers can be considered nothing more than a voltage ratio device. With step down transformers the voltage ratio between primary and secondary will mirror the "turn's ratio" (except for single phase smaller than $1 \mathrm{KVA}$ which have compensated secondary's). A practical application of this 2 to 1 turn's ratio would be a 480 to 240 voltage step down. Note that if the input were 440 volts then the output would be 220 volts. The ratio between input and output voltage will stay constant. Transformers should not be operated at voltages higher than the nameplate rating, but may be operated lower voltages than rated. Because of this it is 
possible to do some non-standard applications using standard transformer. From the vector diagram we can say that if the turns of two primary coils and this coil are equal then very low voltage will be available at the secondary. If the turns of this coil are times of the other two primary coils then there will not be any voltage at the secondary, as the two secondary voltage will oppose each other in the same phase.

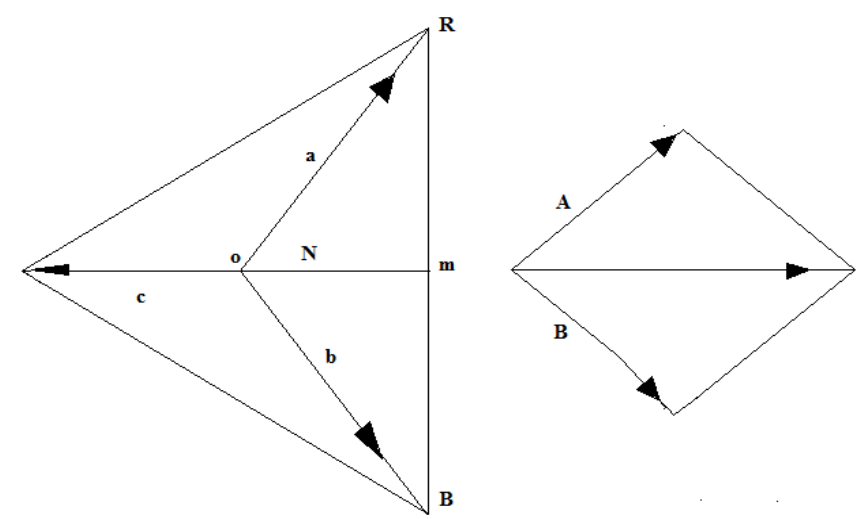

Fig -1: Phasor diagram

It is observed that if, the turns of this newly inserted coil is, taken $21 \%$ of the other two primary coils then with its taps, by varying the secondary voltage the arc can be varied. a and $b$ are two primary coils designed for 400/440v. "c" is a coil with taps, which can be connected to supply through multi-way rotary switches to get the required current range. This coil is having $21 \%$ turns of, a and $b$. Now if some load is applied on the secondary then the voltage across the two coils a and b will decrease and that across $\mathrm{c}$ will increase. The point 0 will shift towards the base of the triangle RYB. If the secondary load is increased then again the voltage across $\mathrm{a}$ and $\mathrm{b}$ drops, across $\mathrm{c}$ increases. The point 0 shifts further towards the base RB of the triangle RYB. And as the voltage across a \& b drops (its phase angle also changes) the secondary voltage too drops. The drop in a secondary voltage is more than proportionate because of the change in phase angle, thus the required negative voltage or drooping characteristics can be obtained. The new coil do has its effect of magnetic coupling on secondary windings on the outer two limbs. It will try to increase the secondary voltage. By doing this we can have a better drooping characteristics. When one rotary switch is used the taps at equal number of turns are taken out and when two rotary switches are used then one will be for main control and other will be for fine control. The choke-less welding transformer has the advantage of better power factor, it is not suitable for CI or stainless steel electrodes, which requires higher striking voltage. This type gives better results for general purpose heavy fabrication work.

Load series motor is a better substitute for an exhaust fan in forced air cooled welding transformer. The forced air cooled welding transformers are provided with a small fractional HP single phase motor of capacitor type or shaded pole type to work as an exhaust fan to cool down the windings. This fan starts running immediately when the welding machine is switched on to the supply. Generally the welding transformer has maximum duty cycle of $60 \%$. The exhaust fan runs at constant speed whatever the current is drawn from the machine for welding or even when no welding work is going on. The load series motor is single phase motor to be connected in series with the load is a current controlled shaded pole motor, designed in such a way that if connected in series with the load, it will run and the speed of such a motor will proportional to the load current that is arc current. This special motor is very suitable for forced air cooled welding transformer. The ordinary exhaust fan can be very easily replaced by the load series motor. [2]

\subsection{Specification:}

\section{CHOKELESS WELDING TRANSFORMER WITH LOAD SERIES MOTOR}

Voltage rating $=440 \mathrm{~V}$

Current rating $=250 \mathrm{~A}$

General duty cycle $=60 \%$

Current density $=5-10 \mathrm{~A} / \mathrm{mm}^{\wedge} 2$

Flux density, For C.R.N.G.O. grade $=1.3-1.5 \mathrm{~Wb} / \mathrm{m}^{\wedge} 2$

Type of cooling $=$ Air forced

Supply = Three phase-400/440V, $50 \mathrm{~Hz}$

OC voltage $=30-60$ volts

Power factor $=0.7$

Wattage $=40 \mathrm{~W}$

Poles $=4$ pole

Frequency $=50 \mathrm{~Hz}$

Speed $=1500$ RPM

\subsection{Advantages}

\section{Better Arc Stability}

2. Heating and Cooling are Proportionate.

3. Reduced no load losses.

4. Improved power factor.

5. Size is compact.

6. More energy saving.

7. Cost is very less.

8. Current Control is easy with the help of Rotary switch.

9. Cooling system is more effective.

10. High Efficiency

\section{CONCLUSION}

Overall performance the machine is very useful in small scale as well as big industries. As the cost of this welding machine is nearly $50 \%-60 \%$ less than the ordinary three phase welding transformer. The overall energy conservation is more. Also the size of the machine is reduced. By using load series motor reduces no load losses and also increases efficiency. So that, the use of choke less welding transformer with load series motor, is advantageous and convenient. 


\section{REFERENCES}

[1]. "Ratings of Oil Power Transformer in Different Cooling Modes" by Radakovic. Z.; Sorgic. M. ; Van der Veken, W. ; Claessens, G.

[2].Text book "Welding Transformer" by Mr.S.J.Kulkarni. [3]. "Electrical Engg. Design Manual" by Mr. Parker Smith, Mr. M.G.Say

[4]. "Welding Process Technology" by P. T. Hould Croft.

\section{BIOGRAPHIES}

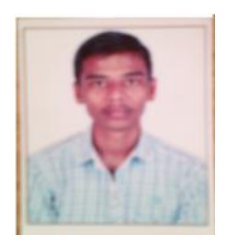

Name: Shivanand B. Katagar, Students of Sharad institute of technology college of engineering, Yadrav.

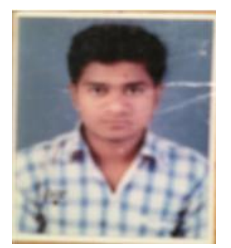

Name: Sharad R. Jadhav, Students of Sharad institute of technology college of engineering, Yadrav

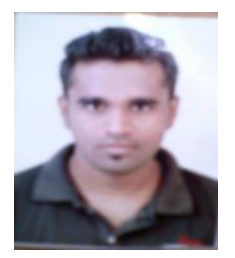

Name: Rajendra M. Salokhe, Students of Sharad institute of technology college of engineering, Yadrav

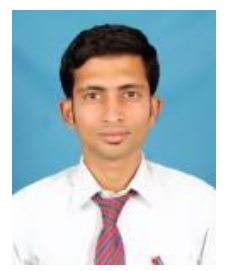

Name: Chetan D. Patil, Assistant Professor of Sharad institute of technology college of engineering, Yadrav 